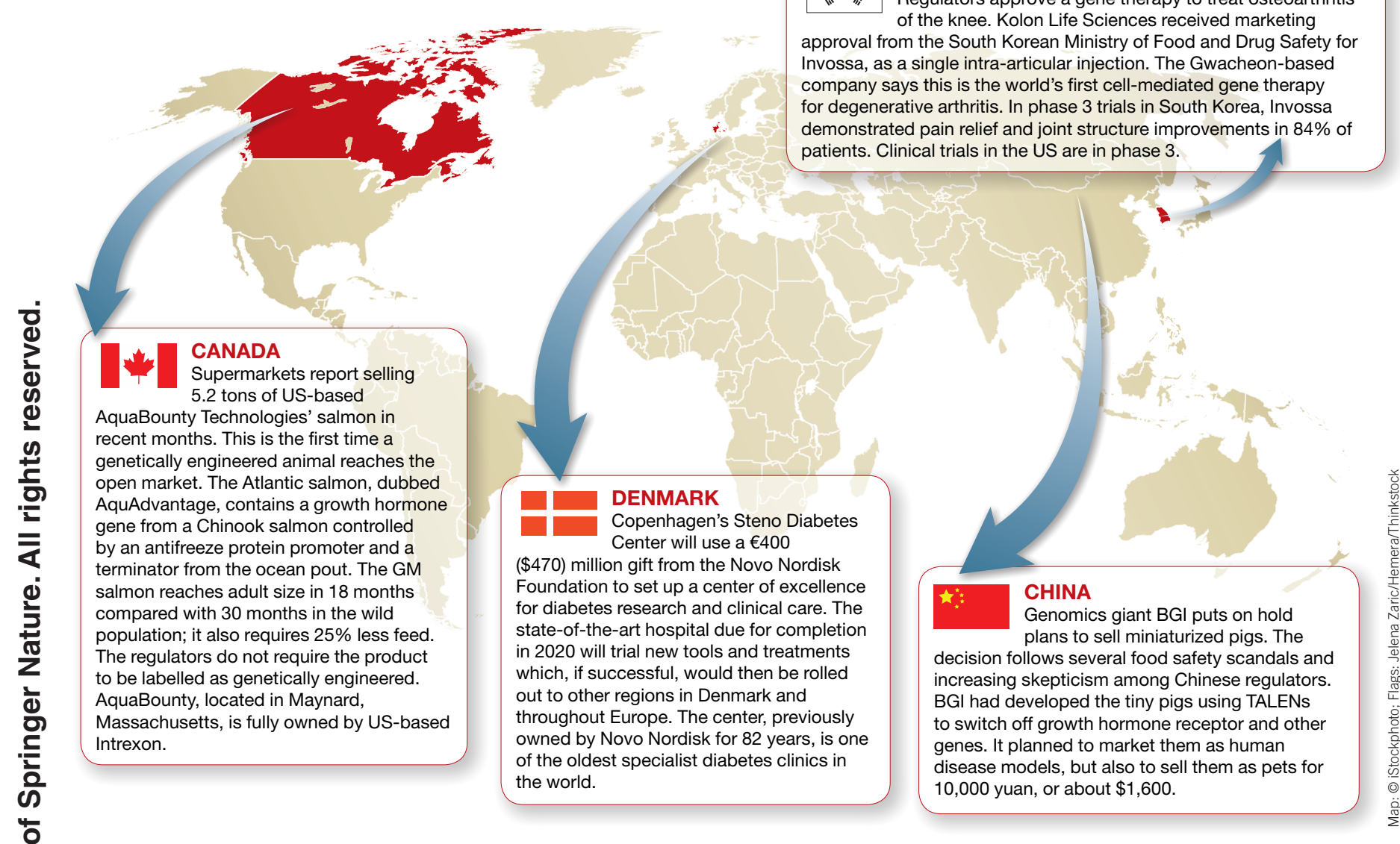

\title{
PODCAST
}

\section{First rounders: Greg Winter}

Greg Winter is the Master of Trinity College, Cambridge, and a serial entrepreneur who co-founded Cambridge Antibody Technology. Much of his career was spent at the Medical Research Council, and his research led to humanized monoclonal antibodies. His conversation with Nature Biotechnology covers growing up in west Africa, how suffering an attack in the street led to a breakthrough in the lab, and the state of UK biotech. http://www.nature.com/nbt/podcast/index.html 